\title{
Sex differences in the duration of visual attention'
}

BRUCE T. LECKART, OHIO UNIVERSITY

KENNETH R. KEELING AND PAUL BAKAN, MICHIGAN STATE UNIVERSITY

Normal adult males and females looked at a series of photographs containing either a single adult male or female. Ss viewed each picture for as long as they wished. Assuming that measures of the duration of attention would reflect $S_{s}$ attraction for the opposite sex, it was hypothesized that $S$ s would spend relatively more time viewing photographs of the opposite sex. The results failed to support the hypothesis. Although males did not differentially attend to the stimuli, females looked significantly longer at the females than they did at the males. The results were interpreted in terms of the "overt sexual content" of the stimuli and socially conditioned attentiveness and inattentiveness.

Attentional behavior has been a topic of interest to psychology since the last half of the nineteenth century. Recent research has demonstrated that the duration of visual attention depends upon stimulus, environmental, and subject variables. It has, for example, been shown that free looking time (the time S spends viewing a stimulus when he can look at it for as long as he wishes) depends upon stimulus complexity (Berlyne, 1957, 1958a, b; Cantor, Cantor, \& Ditrichs, 1963; Leckart \& Bakan, 1965), stimulus novelty (Berlyne, 1958a; Cantor \& Cantor, 1964a, b; Leckart, 1966), the instructions given S (Brown \& Farha, 1966), E's behavior (Martin, 1964), E controlled stimulus presentations (Leckart, Keeling, \& Bakan, 1966), and degree of schizophrenic withdrawal (McReynolds, 1963).

Other studies indicate that at least some individual differences in attention are due to the interaction between subject and stimulus variables. Interaction effects have, for example, been demonstrated with subject variables of "spontaneous sexual behavior"' (Rosenzweig, 1942), sex (Brandt, 1945), homosexuality (Zamansky, 1956), paranoia (Zamansky, 1958), heterosexual interpersonal contact (Christiansen, 1961), and extraversion (Bakan \& Leckart, 1966).

Brandt (1945) had male and female Ss view a single visual target, containing three separate pictures of men and three separate pictures of women. The time spent looking at each picture was recorded with an eye movement camera. The results indicated that male Ss looked longer at pictures of women than atpictures of men, but that female Ss did not differentially attend to the stimuli. However, because only six pictures were used, the possibility exists that sex of the picture was confounded with one or more other stimulus variables.

In a similar study, Zamansky (1956) found that overt male homosexuals showed a stronger preference for male pictures and a stronger avoidance of female pictures than normal males. But, no conclusions were drawn about the normal males per se, although there was a tendency for these Ss to look longer at female than male pictures.

This study was designed to further investigate sex differences in the duration of visual attention by presenting a large sample of male and female pictures to normal male and female Ss in a situation where they could look at the pictures one at a time. By presenting the stimuli successively, instead of simultaneously as had previously been done, the tendency to attend to one stimulus would not be confounded with the tendency to avoid a second stimulus. Assuming that normal Ss are attracted to the opposite sex, and that attending to the opposite sex is socially, if not biologically reinforced, it was expected that Ss would spend relatively more time attending to pictures of members of the opposite sex than to pictures of their own sex.

\section{Subjects}

\section{METHOD}

The Ss were 25 females and 27 males selected from the introductory psychology course at Michigan State University.

\section{Apparafus}

The stimuli consisted of 40 black and white photographs selected from national magazines. Each picture contained a single adult male or female. Half the pictures were of men, half were of women. Each male picture was matched with a female picture so that age, position, action, angle of view, stimulus complexity, and stimulus novelty were controlled.

The photographs were mounted on 3 in. $x 5$ in. unruled white cards and enclosed in clear plastic. The photographs were placed face down in a three-sided wooden box from which $S$ could easily remove one picture at a time. A cardboard box was provided for discarding viewed pictures. $S$ was instructed to view the pictures one at a time, looking at each photograph for as long as he liked. S was also told he would not be asked to remember any of the pictures or anything about them. A second looking task, followed by a rating procedure, gave S closure on the experimental task.

The time spent viewing each picture was recorded semi-automatically with an Esterline-Angus event recorder. Each time S selected a photograph, E pressed a button, producing a pen mark on the moving tape. 
Table 1. Mean Looking Time per Picture of Male and Female Ss Viewing Male and Female Stimuli.

\begin{tabular}{lcc} 
Stimuli & \multicolumn{2}{c}{ Subjects } \\
\hline & Males & Females \\
\hline Males & 5.90 & 6.02 \\
Females & 5.89 & 6.34 \\
\hline
\end{tabular}

Looking time was obtained by measuring the distance between pen marks. Neither E's control button nor the recorder could be seen or heard by $\mathrm{S}$.

All Ss viewed the pictures in the same random order. However, Ss were started at different places in the order except that for each female starting with a particular picture there was also a male starting with that picture.

\section{RESULTS}

For each $\mathrm{S}$ the total time spent looking at the male and female pictures was computed. The mean looking times at male and female pictures for the two groups of Ss are presented in Table 1 . The Picture by Sex interaction is significant $(F=4.550, \mathrm{df}=1 / 50, p<.05)$. Individual comparisons revealed that females looked significantly longer at female pictures than at male pictures $(t=2.91, d f=24, p<.01)$, but that males did not differentially attend to the male and female pictures. Neither the Sex nor Picture main effects were significant.

\section{DISCUSSION}

The results were unexpected in light of previous findings and the present hypothesis. Brandt (1945) found that males looked longer at pictures of females than at pictures of males, but that females showed no difference. The present results are in exactly the opposite direction; females looked longer at pictures of females than at pictures of males, but males showed no difference. Thus, the hypothesis that Ss would spend relatively more time attending to pictures of members of the opposite sex, although not confirmed for male Ss, was clearly rejected for female Ss.

The apparent contradiction between Brandt's data and the present results may be a function of the stimuli used in the two studies. Bullock (1959) obtained results suggesting that the sexual content of a stimulus differentially affects the duration of attention in Ss of different sexes. Thus, when male and female Ss viewed pictures of nude females and landscapes, the results indicated that female Ss were relatively less attentive to the nude females than to the landscapes, but, as one might expect, the male Ss were more attentive to the nude females than to the landscapes. Apparently, "overtly sexual" female stimuli attract the attention of males but repel the attention of females. A comparison of the female pictures used in the present experiment with Brandt's stimuli sug- gested that the latter were more "overtly sexual." Therefore, if the present data are taken as a baseline, it is possible that Brandt's female stimuli increased the males' normal looking time at female stimuli, and suppressed the females' normal looking time at female stimuli. However, additional research is needed to verify these possibilities.

Thus, the present data suggest that in the absence of a modicum of "overt feminine sexuality" that females are more attentive to females than to males, whereas males show no such selectivity in attention. One possible explanation of this finding takes into consideration social roles as determinants of attention. The traditional female role in western society includes passivity witi regard to responding to heterosexual contacts. It is conceivable that this socially conditioned passivity is expressed in free looking time scores. Accordingly, females look less at males than at females because they have been socially conditioned to react to males in a passive or inattentive way. The failure to find a difference in males is similarly explainable. Thus, although males may be conditioned to be more attentive to females when there is a high sexual content in the female stimuli, there is no pressure to be attentive to female stimuli of a low sexual content.

Another possible explanation for the present results is a greater style consciousness in females. Females of college age are attentive to clothing and grooming features of other females. Given pictures that do not contain overt sexuality this might account for the longer looking time of females at the female pictures.

The contradictory results of studies of the subject sex-picture sex interaction suggests the need for more study of picture variables influencing the interaction.

\section{References}

Bakan, P., \& Leckart, B. T. Attention, extraversion, and stimuinspersonality congruence. Percept. \& Psychophys., 1966, 1, 355-357.

Berlyne, D. E. Conflict and information-the ory variables as determinants of human perceptual curiosity. J. exp. Psychol., 1957, 53, 399-404.

Berlyne, D. E. The influence of complexity and novelty in visual figures on orienting responses. J. exp. Psychol., 1958a, 55, 289-296.

Berlyne, D. E. Supplementary report: Complexity and orienting responses with longer exposures. J. exp. Psychol., 1958b, 56 , 183.

Brandt, H. F. The psychology of seeing. New York: Philosophical Library, 1945.

Brown, L. T., \& Farha, w. Some physical determinants of viewing time under three instructional sets. Percept. \& Psychophys., $1966,1,2-4$.

Bullock, D. H. Note on "looking at pictures" behavior. Percept. mot. Skills, 1959, 9, 333.

Cantor, J. H., \& Cantor, G. N. Observing behavior in children as a function of stimulus novelty. Child Develpm., 1964a, 35, 119-128.

Cantor, J. H., \& Cantor, G. N. Children's observing behavior as related to amount and recency of stimulus familiarization. $J$. exp. child. Psychol., 1964b, 1, 241-247.

Cantor, G. N., Cantor, J. H., \& Ditrichs, R. Observing behavior in 
preschool children as a function of stimulus complexity. Child Develpm., 1963, 34, 683-689.

Christiansen, K. C. Response duration as a measure of ambivalent response tendencies. J. Pers., 1961, 29, 115-123.

Leckart, B. T. Looking time: The effects of stimulus complexity and familiarity. Percept. \& Psychophys., 1966, 1, 142-144.

Leckart, B. T., \& Bakan, P. Complexity judgments of photographs and looking time. Percept. mot. Skills, 1965, 21, 16-18.

Leckart, B. T., Keeling, K., \& Bakan, P. The effect of rate of presentation on free Iooking time. Percept. \& Psychophys, 1966, 1, 107-109.

Martin, B. Expression and inhibition of sex motive arousal in college males. J. abnorm. soc. Psychol., 1964, 68, 307-312.

McReynolds, P. Reactions to novel and familiar stimuli as a function of schizophrenic withdrawal. Percept. mot. Skills, 1963,
$16,847-850$.

Rosenzweig. S. The photoscope as an objective device for evaluating sexual interest. Psychosom. Med., 1942, 4, 150-158. Zamansky, H. S. A technique for assessing homosexual tendencies. J. Pers., 1956, 24, 436-448.

Zamansky, H. S. An investigation of the psychoanalytic theory of paranoid delusions. J. Pers., 1958, 26, 410-425.

\section{Note}

1. This research was in part supported by Public Health Service Predoctoral Research Fellowship No. 1-F1-MH-21, 559-01 awarded the senior author during his graduate training at Michigan state University.

(Accepted for publication, September 14, 1966.) 